\title{
CORN STARCH NANOPARTICLES: PREPARATION, CHARACTERIZATION, AND UTILIZATION AS A FAT REPLACER IN SALAD DRESSING
}

\author{
J. KAUR ${ }^{a *}$, G. KAUR ${ }^{b}$ and S. SHARMA ${ }^{a}$ \\ ${ }^{\mathrm{a}}$ Department of Food Science and Technology, Punjab Agricultural University, Ludhiana, 141004. India \\ ${ }^{\mathrm{b}}$ Electron Microscopy and Nanoscience Lab, Punjab Agricultural University, Ludhiana, 141004. India
}

(Received: 11 June 2018; accepted: 16 August 2018)

Corn starch nanoparticles (SNPs) were prepared by ultrasonication of starch for $40 \mathrm{~min}$ at an amplitude of $40 \%$, which modified some properties of starch so that it could be used as a functional ingredient in food products. The cereal SNPs were characterized on the basis of their morphology, particle size, crystallinity, pasting and functional properties. The SNPs were globular in shape as revealed by TEM. There was a decrease in the crystallanity of SNPs, whereas the functional properties were enhanced in SNPs as compared to raw starch. SNPs had a less paste viscosity as compared to raw starch. Salad dressing was prepared by using SNPs as a fat replacer. The prepared salad dressing was examined for colour, viscosity, and sensory attributes. Overall $60 \%$ of fat was replaced using corn SNPs without compromising its quality characteristics.

Keywords: SNPs, ultrasonication, characterization, fat replacer, salad dressing

Having a healthy diet is an important way of maintaining personal health. Consumption of lesser amount of fat is in trend nowadays. It has been reported that overconsumption of fat contributes to increased risk of obesity, type- 2 diabetes, and some types of cancer (SERIN \& SAYAR, 2017). A diet high in saturated fat intake can dramatically raise blood cholesterol level, thus increasing the risk of coronary heart diseases. Whereas, as a food component, fat interacts with other ingredients to impart key sensory and textural benefits (SuDHA et al., 2007). Therefore, a simple reduction in fat lowers food acceptance due to quality losses (PENG \& YAO, 2017).

Low fat or no fat foods are in demand these days, but they are normally associated with some technical problems such as poor flavour, texture, and mouth feel (KEETON, 1994). Therefore, to overcome these problems, modification of food products using fat replacers is often viewed as an effective way (NonAKA, 1997). Fat may also be replaced in foods by reformulating food with lipid, protein, or carbohydrate based ingredient. However, there are two approaches, which may prove the fat replacing functionalities of proteins and carbohydrates. Firstly, both being macromolecules, can yield fat-depleted products with properties similar to that of full fat version. Secondly, both proteins and carbohydrates can be broken down to micro particulates with shapes and sizes similar to fat globules, thus allowing them to behave like fat (PENG \& YAO, 2017). Carbohydrates can provide structural diversity as well as physicochemical properties, so these have been used in some foods for several years to partially or fully replace fat. It has been found that particles less than $3 \mu \mathrm{m}$ in diameter are too small for human tongue to distinguish as individual particles. Thus, these particles are perceived as creamy and smooth (LuCCA \& TEPPER, 1994).

\footnotetext{
* To whom correspondence should be addressed. Phone: +91 7508099339; e-mail: jashan99339@gmail.com
} 
Starch granules have a potential to individually disperse similarly to emulsion droplets, which ultimately brings characteristic sensory and textural properties (RADI et al., 2009). Corn starch is a valuable ingredient to the food industry, being widely used as a thickener and gelling, bulking, and water retention agent (SINGH et al., 2003). However, raw starch has limited applications in the industry due to poor solubility in cold water, high viscosity on gelatinization, and its tendency to retrograde. However, various ways have been introduced as solutions to these disadvantages (e.g. various solvents to dissolve native starch), but modification of starches has always been a better idea. Nanomaterials display unique properties different from large-size particles due to the particle size in the range of nanometres. Particle size has influence over multiple factors: consistency, compaction, the blending of different components, and mixture segregation, in which larger particles remain on the top and smaller ones stay at the bottom. In addition to this, these properties do contribute to the essential properties of food products such as texture, smell, and appearance (Koc \& ERTEKIN, 2014). Thus, preparation of SNPs is one type of starch modification, which has gained a lot of consideration in the food industry for their small size, customized surface area, improved solubility, and multiple functionality due to their ability to control the release characteristics, stability and delivery of several active compounds in foods (WEISS et al., 2006). The viscosity of SNPs decreases with temperature increase and it increases with the increase in SNPs concentration (WU \& PAL, 2018). The possible application of cereal SNPs as fat replacer has already been discussed well by KAUR and co-workers (2018). So because of its small size, the SNPs could be the promising candidates for replacement of fat (KAUR, 2016). Therefore, the aim of this study was to use ultrasonication method to produce corn SNPs, which could be used as a fat replacer in salad dressing to produce a healthy alternative as a new food additive. This is basically a first attempt to use SNPs as a fat replacer as there is no original research present on this topic till date.

\section{Materials and methods}

\subsection{Raw materials}

Native corn starch (approx. 27\% amylose and rest amylopectin) was procured from Sukhjit Starch Mill, NH 1, Phagwara, Punjab. Eggs, vinegar (Tops white vinegar), spices (AGMARK), salad oil (Fortune Sun lite refined sunflower oil), and organic herb mixture (Naturesmith) required for salad dressing preparation were purchased from the local market.

\subsection{Preparation of SNPs}

A quantity of $7.5 \mathrm{~g}$ native corn starch was dispersed in $500 \mathrm{ml}$ distilled water. The dispersion was given ultrasonic treatment using a Probe ultrasonicator for $40 \mathrm{~min}$. The treated sample was then spray dried using SMST-Tall Type Spray Dryer at an inlet temperature of $160{ }^{\circ} \mathrm{C}$, air pressure: 2 bar, feed pump: 16 r.p.m.

\subsection{Physical properties of SNPS}

The morphological examination of cereal SNPs was performed using a transmission electron microscope (TEM H-7650, Hitachi Instruments, Tokyo, Japan). The average size (Z-average size) of nanoparticle in water was measured using a Zetasizer (Nano ZS, Malvern Instruments, Worcestershire, UK) (method by HAAJ and co-workers, 2013). 


\subsection{Functional properties}

Water absorption index and water solubility index (WSI) were determined by the method outlined by ANDERSON and co-workers (1969). Swelling power was measured using a method reported by TESTER and MORRISON (1994).

\subsection{Product preparation and quality evaluation (salad dressing)}

Cereal SNPs were used as a fat replacer to prepare salad dressing. Three types of salad dressings were prepared and evaluated (Control: full fat salad dressing; salad dressing with native starch; and salad dressing with cereal SNPs) (Table 1). Colour was measured with the HunterLab colorimeter. The different reflectance value and colour parameters were recorded. Prepared salad dressing was assessed for sensory attributes (LARMOND, 1970).

Table 1. Formulation of the three types of salad dressing

\begin{tabular}{lccc}
\hline Ingredients, \% & Control full fat & With raw starch & With SNPs \\
\hline Salad oil & 75.0 & 55.0 & 30.0 \\
Egg white & 9.5 & 22.0 & 22.0 \\
Salt & 2.5 & 2.5 & 2.5 \\
Sugar & 2.5 & 2.5 & 2.5 \\
Vinegar & 8.5 & 8.5 & 8.5 \\
Mustard & 2.0 & 2.0 & 2.0 \\
Spice and herbs & 2.5 & 2.5 & 2.5 \\
Raw starch & & 5.0 & \\
Cereal SNPs & - & - & 5.0 \\
\hline
\end{tabular}

Flow sheet for preparation of salad dressing is given below.

Whipping of egg at high speed for $2 \mathrm{~min}$

$\downarrow$

Mixing the dry ingredients ( $2.5 \mathrm{~g}$ salt, $2 \mathrm{~g}$ mustard flour, $2.5 \mathrm{~g}$ sugar)

$\downarrow$

Addition of one third of the total Tops white vinegar ( $8.5 \mathrm{~g}$ )

$$
\downarrow
$$

Addition of sunflower oil (75 g for full fat, $55 \mathrm{~g}$ for raw starch, and $30 \mathrm{~g}$ for SNPs) + starch at slow speed for $5 \mathrm{~min}$ ( $5 \mathrm{~g}$ for raw starch salad dressing and $5 \mathrm{~g}$ in SNPs)

$\downarrow$

Addition of the rest of the vinegar

$\downarrow$

Mixing at medium speed for $2 \mathrm{~min}$

$\downarrow$

Packing in PET jars

\subsection{Statistical analysis}

Data given are means of triplicates. Data collected from these experiments were subjected to statistical analysis (ANOVA) (Gomez \& Gomez, 2010). 


\section{Results and discussion}

\subsection{Characterization of starch nanoparticles}

The SNPs prepared were characterized on the basis of morphology, particle size, crystallinity, and functional properties (WSI and WAI). The granules were having globular shapes and were in the form of clusters (Fig. 1). Ultrasonication fragmented the starch hydrolysates to nanoparticles, the formation of clusters may be due to the tendency of starch particles to aggregate. LiU and co-workers (2009) stated that the SNPs tend to form micro-scale aggregates through van der Waals forces and hydrogen bonds, which could readily sediment as precipitates. With decrease in particle size, the particle surface area increases causing higher affinity with moisture and higher ability to agglomerate (KOC \& ERTEKIN, 2014). Ultrasonication was followed by spray drying to achieve dried powder, also contributing to reduction of particle size (NiAzI \& BROEKHUIS, 2012). When the starch hydrolysates were treated with short and mild ultrasonic treatment ( $40 \%$ amplitude for $5 \mathrm{~min}$ ), the microparticles effectively fragmented to nanoparticles. The ultrasonic treatment increased the transparency (clarity) of the starch suspension, as a result of the size reduction of suspended particles. ZuO and coworkers (2009) reported a similar result for a starch suspension treated by ultrasonication. The elementary size of the nanoparticles forming the clusters was between 20 and $80 \mathrm{~nm}$. The temperature of starch suspensions might rise due to the absorption of ultrasound energy. To minimize the heating effect, on/off cycles of ultrasonication are used in this study. The temperature increase might cause swelling of hydrolysed starch particles (SUSLICK, 1988), which may assist the formation of aggregates resulting in size increase as observed for starch hydrolysates treated by excessive ultrasonication (KIM et al., 2013a).
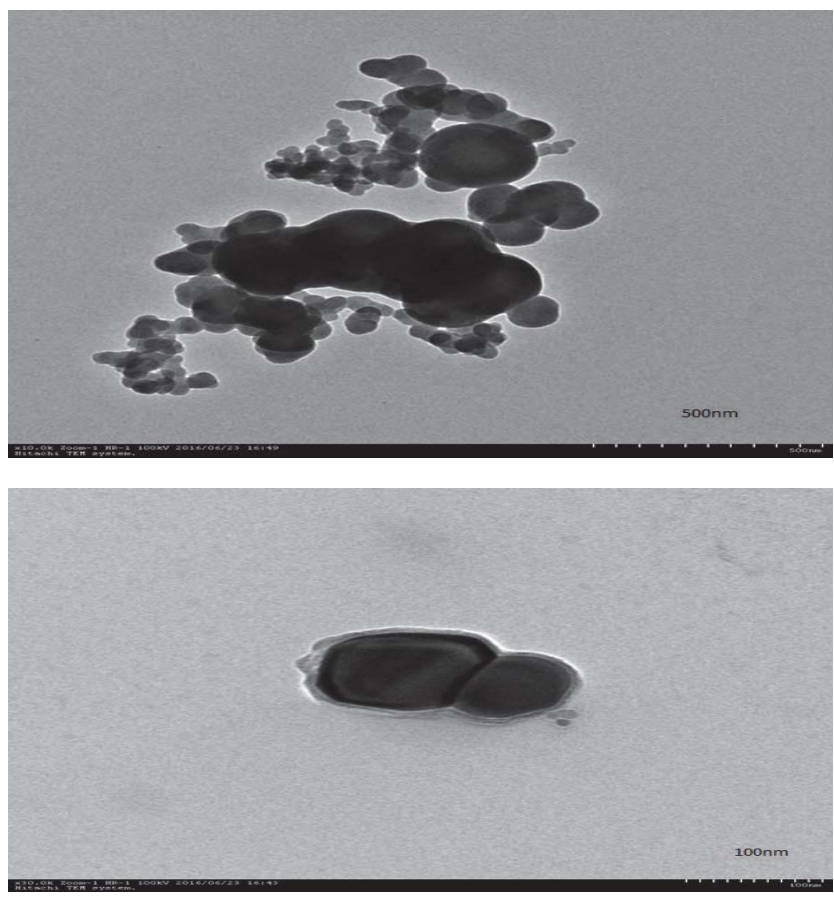

Fig. 1. Transmission electron micrographs of SNPs 
A bimodal size distribution was obtained with a z-average of $3 \mu \mathrm{m}$ and a mean polydispersity of 1.0 for the SNPs prepared by ultrasonication (Fig. 2). The first peak represents a size of $250 \mathrm{~nm}$ and the other peak $2132 \mathrm{~nm}$. Bimodal distribution represents the presence of nanoparticles and the micro-starch particles. Similar results were indicated by HAAJ and co-workers (2013), who found that the initial size of starch particles were $6 \mu \mathrm{m}$, which is rather low, as our SEM observations showed particles in the range of 5-15 $\mu \mathrm{m}$.

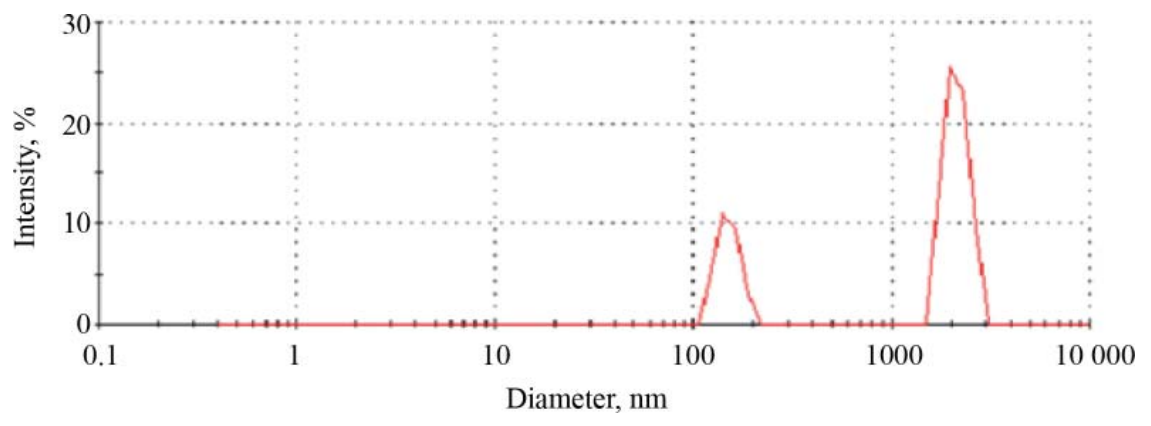

Fig. 2. Particle size distribution of SNPs by intensity

The crystallinity of cereal SNPs is influenced by the inherent properties of starch, such as botanical source, amylose content of starch, crystalline structure, as well as the processing parameter for SNPs preparation such as hydrolysis temperature and ultrasonic power. Figure 3 shows the comparison of X-ray diffractograms of raw starch and cereal SNPs. The raw starch exhibits a sharp peak at about $23^{\circ} 2 \theta$ and a doublet peak at around $17^{\circ}$ and $18^{\circ} 2 \theta$ (Fig. $3 \mathrm{~A})$. The results are in accordance with the work done by KIM and co-workers (2013b), in which raw corn starch and SNPs exhibited diffraction patterns with peaks at Bragg angle (20) $15^{\circ}, 17^{\circ}, 18^{\circ}$, and $23^{\circ}$. Important changes in the X-ray spectra were noted for starch under the effect of ultrasonication. After $40 \mathrm{~min}$ ultrasonication the diffraction peaks decreased in intensity. However, in SNPs, and broad peaks with low height were observed, which clearly depicts that after treatment starch loses its crystallinity. Some broader peaks were seen at around $15^{\circ}-24^{\circ} 2 \theta$ for SNPs (Fig. 3B). This might be explained by that prolonged ultrasonication of the starch granules might result in serious disruption of the crystalline structure of clustered amylopectin. Similar results were obtained by HAAJ and co-workers (2013), SNPs prepared by ultrasonic treatment of aqueous suspension of native starch for 75 min showed low crystallinity phase in the diffraction spectra. Similar results were observed in another study, where a decrease in crystallinity of waxy maize starch was seen after acid hydrolysis followed by ultrasonic treatment (KIM et al., 2013a).

\subsection{Functional properties}

Functional properties of raw starch and corn SNPs are depicted in Table 2. Water absorption index (WAI) ( $\left.\mathrm{g} \mathrm{g}^{-1}\right)$ measures the volume occupied by the granule or starch polymer after swelling in excess water. The water absorption index of raw starch was $3.52 \mathrm{~g} \mathrm{~g}^{-1}$, which was almost double for corn starch nanoparticle formation $\left(5.82 \mathrm{~g} \mathrm{~g}^{-1}\right)$. This can be associated to the extensive hydrolysis of glycosidic linkages, yielding shorter molecules such as 
monosaccharides, disaccharides, and small oligosaccharides, which are more hygroscopic than the polysaccharide due to the larger number of free hydroxyl groups (PÉREz \& BERTOFT, 2010). WSI of raw starch and corn SNPs differed significantly; WSI of SNPs was higher than of raw starch. Water binding capacity of corn starch increased up to $1.49 \mathrm{~g} \mathrm{~g}^{-1}$ from $1.20 \mathrm{~g} \mathrm{~g}^{-1}$, after modifying by the pre-gelatinization method (Yousif et al., 2012). Results also showed that the maximum solubility, $44.85 \%$, was achieved by dextrinized corn starch after heat treatment at $90{ }^{\circ} \mathrm{C}$, which means about 5.9-fold increase in solubility as compared to native starch. Swelling power was also higher in case of SNPs. Results were in accordance with the findings of Goncalves and co-workers (2014), SNPs obtained from Araucaria angustifolia by acid hydrolysis and ultrasonication presented increase in solubility. Swelling capacity of chemically modified starch increases, which might be due to the weakening of the intragranular binding forces within the starchy granule, which offers less restriction to the swelling of modified starches (ADEBOWALE et al., 2005).

A

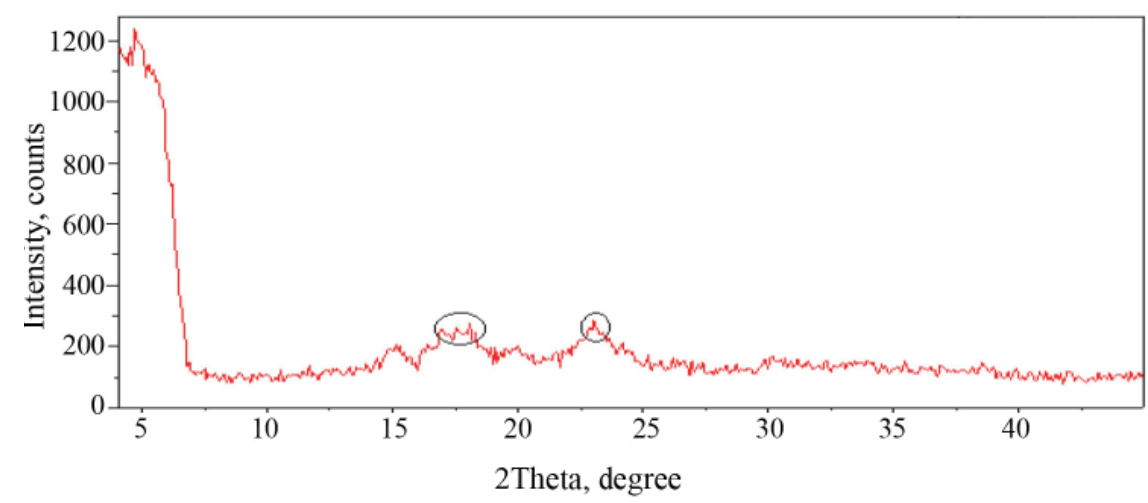

B

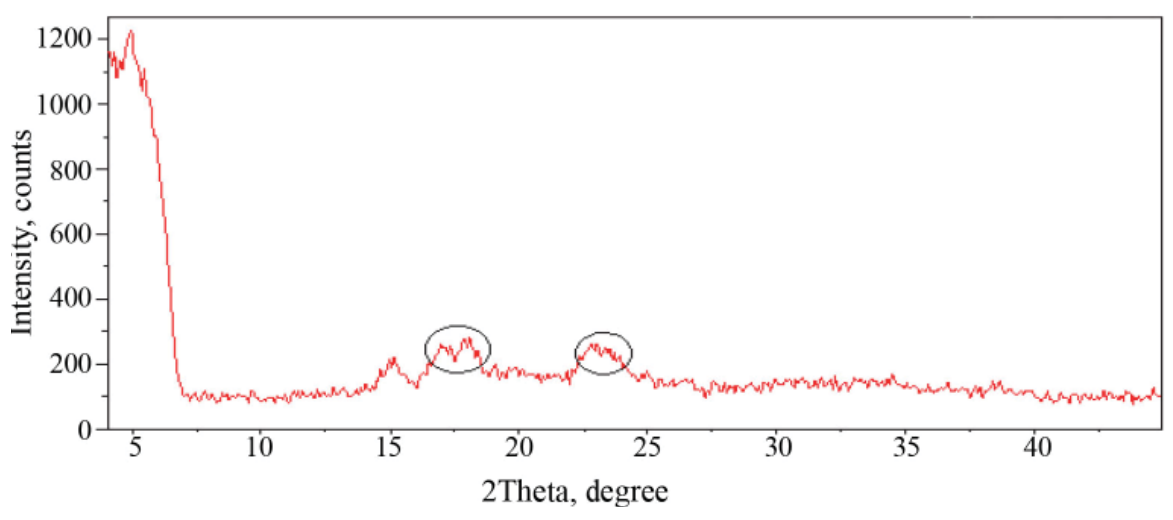

Fig. 3. A: X-ray diffraction pattern of raw starch, B: X-ray diffraction pattern of corn SNPs 
Table 2. Functional properties of raw starch and SNPs

\begin{tabular}{lccc}
\hline Type of starch & \multicolumn{3}{c}{ Functional properties } \\
\cline { 2 - 4 } & WAI $\left(\mathrm{g} \mathrm{g}^{-1)}\right.$ & WSI $(\%)$ & Swelling power (\%) \\
\hline Raw starch & $3.52 \pm 0.01$ & $12.3 \pm 0.09$ & $5.31 \pm 0.02$ \\
Cereal SNPs & $5.82 \pm 0.02$ & $14.7 \pm 0.07$ & $8.45 \pm 0.04$ \\
CD $(0.05)$ & 0.036 & 0.183 & 0.072 \\
\hline
\end{tabular}

CD: critical difference. Treatments were found significant at $5 \%$ level of significance.

\subsection{Quality evaluation of salad dressing}

Colour profiles of three types of salad dressings are connoted in Figure 4. Salad dressing prepared with raw starch had maximum $L$ value (83.25), and $b^{*}(21.55)$ value was maximum for salad dressing prepared with cereal SNPs, whereas a* $(-2.19)$ was maximum in case of salad dressing prepared with full fat (Table 3). Sensory attribute score of salad dressing is shown in Figure 5. Significant variation in overall acceptability score was observed in salad dressing with full fat (7.65), with native starch (7.81), and with cereal SNPs (7.9). Samples with cereal SNPs were most desirable because of better mouthfeel (Table 4). Consistency of the salad dressing having cereal SNPs was significantly higher than the salad dressing prepared with raw starch, and could make a proper and desirable coating over the salad. It has already been reported earlier that in model emulsions, the release rate of flavour and aroma increases with fat reduction (PENG \& YAO, 2017).

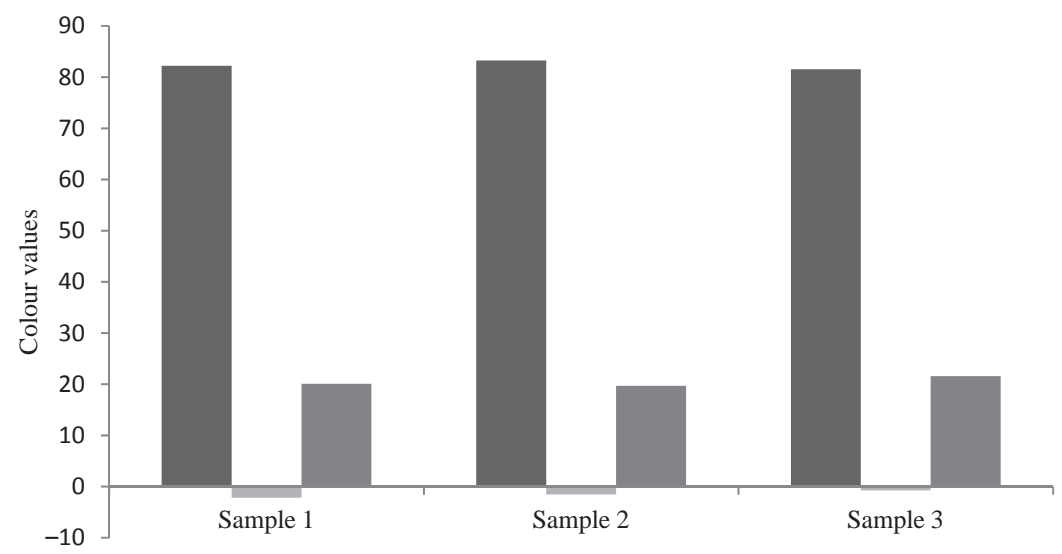

Fig. 4. Colour score of salad dressing ( $\square:$ L; $\sqsubset:$ a; $\varpi:$ b; Sample 1: full fat salad dressing; sample 2: salad dressing with raw starch; sample 3: salad dressing with cereal SNPs) 


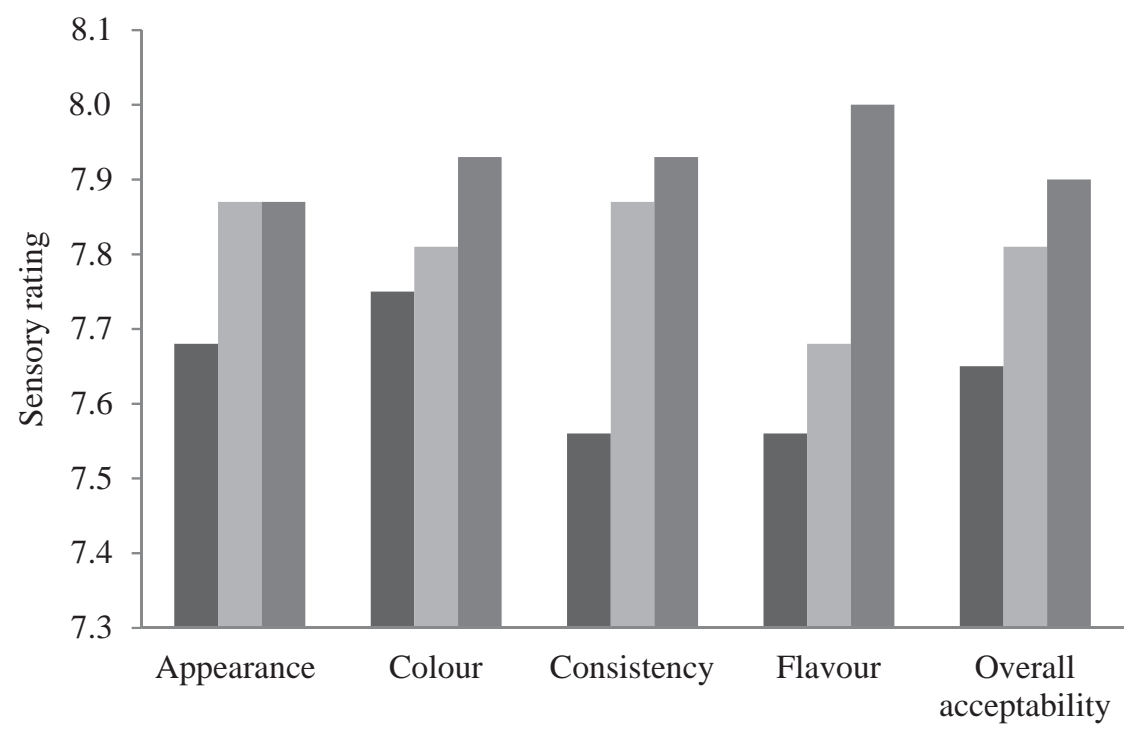

Fig. 5. Sensory attribute score of salad dressing (: Sample 1: full fat salad dressing; $:$ : sample 2: salad dressing with raw starch; ㄷ: sample 3: salad dressing with cereal SNPs)

Table 3. Colour analysis of raw starch and SNPs

\begin{tabular}{lccc}
\hline & $\mathrm{L}$ & $\mathrm{a}$ & $\mathrm{b}$ \\
\hline Raw starch & 82.21 & -2.19 & 20.06 \\
SNPs & 81.53 & -0.75 & 21.55 \\
\hline
\end{tabular}

Treatments were significant at $5 \%$ level of significance with CD $(0.05)=0.023$

Table 4. Sensory analysis of salad dressings

\begin{tabular}{lcccc}
\hline & Appearance & Colour & Consistency & Flavour \\
\hline Raw starch & 7.68 & 7.75 & 7.56 & 7.56 \\
SNPs & 7.87 & 7.93 & 7.93 & 8 \\
Coefficient of variance (CV) & 8.651 & 10.892 & 11.405 & 10.142 \\
\hline
\end{tabular}

Treatments were found non-significant (mean values)

\section{Conclusions}

An efficient method has been introduced for the preparation of SNPs using a physical method without use of any chemicals. On the basis of characterization and quality evaluation of SNPs, it can be inferred that the starch granules have undergone modification, which imparts properties needed to be utilized as a food additive. SNPs can replace the fat in salad dressing up to $60 \%$ as compared to full fat salad dressing. To the best of our knowledge, this is the first report concerning the utilization of SNPs as a fat replacer in a food item, the results are quite convincing. 


\section{References}

Adebowale, K.O., Olu-Owolabi, B.I., Olawumi, E.K. \& Lawal, O.S. (2005): Functional properties of native, physically and chemically modified breadfruit (Artocarpus artilis) starch. Ind. Crops Prod., 21, 343-351.

Anderson, R.A., Conway, H.F. \& Griffin, E.L. (1969): Gelatinization of corn grits by roll and extrusion cooking. J. Cereal Sci., 14, 4-12.

Gomez, A.K. \& Gomez, A.A. (2010): Statistical procedures for agricultural research. John Wiley and Sons. New York. USA, 680 pages.

Goncalves, P.M., Norena, C.P.Z., Silveira, N.P. \& Brandelli, A. (2014): Characterization of SNPs obtained from Araucaria angustifolia seeds by acid hydrolysis and ultrasound. LWT - Food Sci. Technol., 58(1), 21-27.

HaAj, S.B., Magnin, A., Petrier, C. \& Boufi, S. (2013): SNPs formation via high power ultrasonication. Carbohyd. Polym., 92, 1625-1632.

Kaur, J. (2016): Cereal starch nanoparticles: Preparation, characterization and utilization. MSc Thesis, Punjab Agricultural University

Kaur, J., Kaur, G., Sharma, S. \& Jeet, K. (2016): Cereal starch nanoparticles - A prospective food additive: A review. Crit. Rev. Food Sci. Nutr., 58(7), 1097-1107.

KeEton, J.T. (1994): Low-fat meat products-technological problems with processing. Meat Sci., 36, $261-276$.

Kim, H.Y., HAn, J.A., Kweon, D.K., PARK, J.D. \& LiM, S.T. (2013a): Effect of ultrasonic treatments on nanoparticle preparation of acid-hydrolysed waxy maize starch. Carbohyd. Polym., 93, 582-588.

KIM, H.Y., PARK, D.J., KIM, J.Y. \& LiM, S.T. (2013b): Preparation of crystalline SNPs using cold acid hydrolysis and ultrasonication. Carbohyd. Polym., 98, 295-301.

KIM, H.Y., PARK, S.S. \& Lim, S.T. (2014): Preparation, characterization and utilization of SNPs. Colloid Surface B, $126,607-620$.

Koc, B. \& ERTEKIn, F.K. (2014): The effect of spray drying processing conditions on physical properties of spray dried maltodextrin. FoodBalt 2014 Conference Proceedings, pp. 243-247.

Larmond, E. (1970): Methods of sensory evaluation of food. Can. Dept. Agric. Publ., 1284E. 104 pages.

Liu, D., Wu, Q., Chen, H. \& Chang, P.R. (2009): Transitional properties of starch colloid with particle size reduction from micro- to nanometer. J. Colloid Interf. Sci., 339, 117-124.

LuccA, A. \& Tepper, B.J. (1994): Fat replacers and the functionality of fat in foods. Trends Food Sci. Tech., 5, 12-19.

Niazi, M.B.K. \& Broekhuis, A.A. (2012): Production of amorphous starch powders by solution spray drying. J. Appl. Polym. Sci., 126, E143-E153.

NonAKa, H.H. (1997): Plant carbohydrate derived products as fat replacers and calorie reducers. Cereal Food. World, 42, 377-378.

Peng, X. \& Yao, Y. (2017): Carbohydrates as fat replacers. Annu. Rev. Food Sci. T., 8, 331-351.

Pérez, S. \& Bertoft, E. (2010): The molecular structures of starch components and their contribution to the architecture of starch granules: a comprehensive review. Starch, 62, 389-420.

Radi, M., Niakousari, M. \& Amiri, S. (2009): Physicochemical, textural and sensory properties of low-fat yogurt produced by using modified wheat starch as a fat replacer. J. Appl. Sci. 9(11), 2194-2197.

SERIN, S. \& SAYAR, S. (2017): The effect of the replacement of fat with carbohydrate-based fat replacers on the dough properties and quality of the baked pogaca: A traditional high-fat bakery product. Food Sci. Tech. - Brazil., 37(1), 25-32.

Singh, N., Singh, J., Kaur, L., Sodhi, N.S. \& Gill, B.S. (2003): Morphological, thermal and rheological properties of starches from different botanical sources. Food Chem., 81, 219-231.

Sudha, M.L., Srivastava, A.K., Vetrimani, R. \& Leelavathi, K. (2007): Fat replacement in soft dough biscuits: Its implications on dough rheology and biscuit quality. J. Food Eng., 80(3), 922-930.

SusLick, K.S. (Ed.) (1988): Ultrasound: Its chemical, physical, and biological effects. VCH Press, New York. 336 pages.

Tester, R.F. \& Morrison, W.R. (1994): Properties of damaged starch granules. V. Composition and swelling of fractions of wheat starch in water at various temperatures. J. Cereal Sci., 20, 175-181.

Weiss, J., Takhistov, P. \& McClements, D.J. (2006): Functional materials in food nanotechnology. J. Food Sci., 71, R107-R116.

Wu, Y. \& PAL, R. (2018): Rheology and pipeline flow behaviour of starch nanoparticle dispersion. J. Nanofluids, 7 , $1-10$.

Yousif, E.I., Gadallah, M.G.E. \& Sorour, A.M. (2012): Physico-chemical and rheological properties of modified corn starches and its effect on noodle quality. Ann. Agric. Sci., 57, 19-27.

Zuo, J.Y., Knoerzer, K., Mawson, R., Kentish, S.O. \& Ashokkumar, M. (2009): The pasting properties of sonicated waxy rice starch suspensions. Ultrason. Sonochem., 16, 462-468.

Acta Alimentaria 48, 2019 